\title{
Larvae of Ixodes ricinus transmit Borrelia afzelii and $B$. miyamotoi to vertebrate hosts
}

\author{
Gilian van Duijvendijk ${ }^{*}$, Claudia Coipan ${ }^{2}$, Alex Wagemakers ${ }^{3}$, Manoj Fonville ${ }^{2}$, Jasmin Ersöz ${ }^{3}$, Anneke Oei ${ }^{4}$, \\ Gábor Földvári', Joppe Hovius ${ }^{5}$, Willem Takken ${ }^{1}$ and Hein Sprong ${ }^{2}$
}

\begin{abstract}
Background: Lyme borreliosis is the most common tick-borne human disease and is caused by Borrelia burgdorferi sensu lato (s.l.). Borrelia miyamotoi, a relapsing fever spirochaete, is transmitted transovarially, whereas this has not been shown for B. burgdorferi (s.l). Therefore, B. burgdorferi (s.l) is considered to cycle from nymphs to larvae through vertebrates. Larvae of Ixodes ricinus are occasionally B. burgdorferi (s.l) infected, but their vector competence has never been studied.

Methods: We challenged 20 laboratory mice with field-collected larvae of I. ricinus. A subset of these larvae was analysed for infections with B. burgdorferi (s.l) and B. miyamotoi. After three to four challenges, mice were sacrificed and skin and spleen samples were analysed for infection by PCR and culture.

Results: Field-collected larvae were naturally infected with B. burgdorferi (s.) (0.62 \%) and B. miyamotoi (2.0\%). Two mice acquired a B. afzelii infection and four mice acquired a B. miyamotoi infection during the larval challenges.

Conclusion: We showed that larvae of I. ricinus transmit B. afzelii and B. miyamotoi to rodents and calculated that rodents have a considerable chance of acquiring infections from larvae compared to nymphs. As a result, B. afzelii can cycle between larvae through rodents. Our findings further imply that larval bites on humans, which easily go unnoticed, can cause Lyme borreliosis and Borrelia miyamotoi disease.
\end{abstract}

Keywords: Ixodes ricinus, Larva, Borrelia burgdorferi, Borrelia miyamotoi, Transmission, Infection, Vector, Tick, Rodent

\section{Background}

Lyme borreliosis is the most common vector-borne human disease in the northern hemisphere and is caused by Borrelia burgdorferi sensu lato (s.l.) [1]. Borrelia miyamotoi is an emerging pathogen which can cause relapsing fever, tentatively called Borrelia miyamotoi disease in humans [2, 3]. In Europe, both pathogens are transmitted by Ixodes ricinus. This tick species hatches from the egg as a larva, which feeds from a vertebrate host before moulting into a nymph. Nymphs feed again from a vertebrate host before moulting into an adult. It is generally believed that larvae of I. ricinus are not infected with B. burgdorferi (s.l.) $[4,5]$ and can only

\footnotetext{
* Correspondence: gilian.vanduijvendijk@wur.nl

${ }^{1}$ Laboratory of Entomology, Wageningen University, PO box 166700AA,

Wageningen, The Netherlands

Full list of author information is available at the end of the article
}

become infected during a blood meal from an infected host [6] or during a blood meal in the vicinity of an infected nymph feeding on an uninfected host, known as co-feeding $[7,8]$. The infected engorged larvae then moult into infected nymphs, which can transmit the spirochaetes to new hosts [9]. Rodents are the most frequently used hosts by larvae and are reservoirs for $B$. afzelii [10]. However, B. burgdorferi (s.l.) is also, but rarely, found in questing larvae [11-14]. Borrelia miyamotoi, on the other hand, can be transmitted transovarially from female tick to larva [15] but is only shortly maintained in rodents [16]. Presence of a pathogenic microorganism in a tick does not necessarily mean that the tick is also competent as a vector [17]. On rodents, larval tick burden is much higher than nymphal tick burden, while adult $I$. ricinus rarely feed on rodents [18]. Humans are also bitten by larvae, with an estimated of 
at least 30,000 larval bites - out of 1.1 million tick bites in The Netherlands annually [19]. Therefore, even a low $B$. burgdorferi (s.l) infection rate in larvae will be of importance to the enzootic transmission cycle of $B$. burgdorferi (s.l) [14] and human disease risk.

The aim of this study was to examine whether the larvae of $I$. ricinus can transmit B. burgdorferi (s.l) and $B$. miyamotoi to vertebrate hosts.

\section{Methods}

\section{Study organisms}

Twenty-eight male Naval Medical Research Institute (NMRI) mice 2 months-old were used. Experiment 1 consisted of 10 treatment and two control mice and experiment 2 consisted of 10 treatment and six control mice. Mice were housed individually in unmodified Makrolon type II cages with ad libitum water and food. Cages were suspended over pans filled with water and with petroleum jelly on the edge.

Larvae of $I$. ricinus were captured at five locations (Buunderkamp, Grebbeberg, Sysselt, Bilderberg and Planken Wambuis) near Wageningen, The Netherlands (Table 1). All larvae were captured in June-September 2014 within 2 weeks prior to each challenge (see below) or pathogen detection. All locations consisted of mixed forests dominated by Scots pine (Pinus sylvestris). A $1 \times 1 \mathrm{~m}$ blanket was dragged over the vegetation [20] and attached larvae were collected using an aspirator. A subset of these questing larvae were individually analysed for natural infections with B. burgdorferi (s.l) and $B$. miyamotoi. Larvae were stored in groups of 200 in ventilated $50 \mathrm{ml}$ tubes and stored at room temperature, $90 \%$ relative humidity $(\mathrm{RH})$ and natural day length until further use. Tick life-cycle stage was confirmed using a microscope.

\section{Challenges with larvae}

Mice were challenged with 200 larvae on the head and neck under anaesthesia (60 $\mathrm{mg} / \mathrm{kg}$ pentobarbital, i.p.) at 2 -week intervals. In experiment 1 , five groups of two mice were subjected to four challenges with 200 larvae collected from five different locations (Table 1). Two control mice received no larval challenge. In experiment 2 , five groups of two mice were similarly subjected to three challenges with 200 field-collected larvae while six control mice were not challenged. Engorged larvae were collected from the pans with water four and seven days after each challenge and dried on filter paper for $2 \mathrm{~h}$. These larvae were then housed individually in ventilated $0.2 \mathrm{ml}$ Eppendorf tubes at $20{ }^{\circ} \mathrm{C}, 90 \% \mathrm{RH}$ and a day length of $14 \mathrm{~h}$. Engorged larvae of experiment 1 were checked monthly, and 2 months after moulting, the emerged nymphs were stored at $-20{ }^{\circ} \mathrm{C}$ until further use. Larvae that did not moult and larvae from experiment 2 were excluded from the molecular analysis.

\section{Collection of mouse tissue}

An ear biopsy was collected from each mouse with sterile scissors and tweezers 1 week before challenge 1 . One week after challenge 4 in experiment 1 and 3 weeks after challenge 3 in experiment 2 , mice were sacrificed by cardiac bleed followed by cervical dislocation under anaesthesia $(60 \mathrm{mg} / \mathrm{kg}$ pentobarbital, i.p.), after which two ear biopsies and a spleen sample were collected. All tissue samples were stored in $70 \%$ ethanol at $-20{ }^{\circ} \mathrm{C}$ until further use.

\section{Ethical approval}

All experiments were approved by the Ethical committee of Wageningen University (number 2013136).

\section{Natural tick burden on field-collected rodents}

In 2013 and 2014, rodent life traps were placed with $5 \mathrm{~m}$ inter-trap distance in grids of $12 * 12$ and $6 * 12$, respectively, at two locations in a forest near Wageningen, The Netherlands $\left(51^{\circ} 59^{\prime} 35.43^{\prime \prime} \mathrm{N}, 5^{\circ} 43^{\prime} 42.06 " \mathrm{E}\right)$ and $\left(51^{\circ}\right.$ $\left.59^{\prime} 37.22^{\prime \prime} \mathrm{N}, 5^{\circ} 43^{\prime} 22.08^{\prime \prime} \mathrm{E}\right)$. Traps were set at $15: 30 \mathrm{~h}$ and inspected the next day at $08.30 \mathrm{~h}$ at 3-week intervals from May till November. Tick burdens of trapped wood mice (Apodemus sylvaticus) and bank voles (Myodes glareolus) were determined by searching the head, ears, snout, belly, legs, armpits, throat and tail.

Table 1 Origin, mouse numbers and infection rates of questing larvae

\begin{tabular}{lllll}
\hline Location & Coordinates & Mouse & B. burgdorferi & B. miyamotoi \\
\hline Buunderkamp & $52^{\circ} 00^{\prime} 46^{\prime \prime} \mathrm{N}, 5^{\circ} 45^{\prime} 42^{\prime} \mathrm{E}$ & $1-2,13-14$ & $1.12(3 / 267)$ & $2.25(6 / 267)$ \\
Grebbeberg & $51^{\circ} 57^{\prime} 10^{\prime \prime} \mathrm{N}, 5^{\circ} 35^{\prime} 25^{\prime \prime E}$ & $3-4,15-16$ & $1.29(3 / 233)$ & $0.43(1 / 233)$ \\
Sysselt & $52^{\circ} 01^{\prime} 40^{\prime \prime} \mathrm{N}, 5^{\circ} 41^{\prime} 26^{\prime \prime} \mathrm{E}$ & $5-6,17-18$ & $0.39(1 / 257)$ & $0.39(1 / 257)$ \\
Bilderberg & $51^{\circ} 59^{\prime} 55^{\prime \prime} \mathrm{N}, 5^{\circ} 48^{\prime} 34 \mathrm{E} \mathrm{E}$ & $7-8,19-20$ & $0(0 / 362)$ & $2.49(9 / 362)$ \\
Planken Wambuis & $52^{\circ} 01^{\prime} 36^{\prime \prime} \mathrm{N}, 5^{\circ} 48^{\prime} 55^{\prime \prime} \mathrm{E}$ & $9-10,21-22$ & $0.59(2 / 337)$ & $3.56(12 / 337)$ \\
Mean & & & $0.62(9 / 1456)$ & $1.99(29 / 1456)$ \\
\hline
\end{tabular}

Questing larvae were collected at five locations. Coordinates, mouse numbers and B. burgdorferi (s.I) and B. miyamotoi infection rates (infected/analysed) of questing larvae are shown per location 


\section{Pathogen detection}

In experiment 2, mouse spleens and ears collected at the end of the experiment were cultured in MKP-F medium as described in detail previously [21]. In short: a $4 \mathrm{~mm}$ tissue biopsy was disinfected and placed in $7 \mathrm{ml}$ Modified Kelly-Pettenkofer medium containing rifampicin, fosfomycin and amphotericin B as antibiotics. Cultures were incubated at $33{ }^{\circ} \mathrm{C}$ and checked weekly for motile spirochaetes using a dark-field microscope at 250x magnification. After 3 weeks $500 \mu \mathrm{l}$ of medium was inoculated into a new tube containing $7 \mathrm{ml}$ of culturing medium. This was repeated three times. DNA from the cultures containing motile spirochaetes, tissue samples and moulted nymphs were extracted using the Qiagen DNeasy Blood \& Tissue Kit [22]. DNA from questing larvae was extracted by alkaline lysis [23]. The presence of B. burgdorferi (s.l) DNA was detected with a duplex quantitative PCR using fragments of the outer membrane protein A gene and the flagellin $\mathrm{B}$ gene as targets [24]. In the same qPCR, B. miyamotoi could specifically be detected with primers and probe based on the flagellin gene for detection of the bacteria. The presence of Neoehrlichia mikurensis and Anaplasma phagocytophilum was detected as described [22]. Multi-Locus Sequence
Typing on the Borrelia cultures was performed as described [25].

\section{Data analysis}

Infection rates of questing larvae and emerged nymphs were compared using a generalized linear model (GLM, assuming binomial distribution with logit link function) in SAS statistical software, version 9.3.

\section{Results}

Infection rates of field-collected larvae in nature and after feeding on laboratory mice

A subset of 1456 field-collected questing larvae were analysed for infection. In experiment 1, 1897 engorged fieldcollected larvae that fed on laboratory mice were collected, from which 1823 (96\%) moulted into nymphs. Borrelia burgdorferi (s.l) infection rate increased from $0.62 \%(9 / 1,456)$ in questing larvae to $1.65 \%(30 / 1,823)$ in larvae that moulted into nymphs after feeding (Tables 1 and 2, likelihood ratio chi-square $7.79, \mathrm{df}=1, P=0.005$ ). Borrelia miyamotoi infection rate of questing larvae $(1.99 \%, 29 / 1,456)$ and larvae that moulted into nymphs after feeding $(1.76 \%, 32 / 1,823)$ did not differ (likelihood ratio chi-square $0.25, \mathrm{df}=1, P=0.619)$. No questing larvae

Table 2 Infection rates (infected/analysed) of ticks after feeding on mice of experiment 1

\begin{tabular}{|c|c|c|c|c|c|c|}
\hline & Mouse & Challenge 1 & Challenge 2 & Challenge 3 & Challenge 4 & PCR-positive tissues \\
\hline \multirow[t]{11}{*}{ B. burgdorferi (s.l) } & 1 & $1.3(1 / 75)$ & $0(0 / 81)$ & $2.2(1 / 45)$ & $0(0 / 48)$ & - \\
\hline & 2 & $0(0 / 32)$ & $0(0 / 39)$ & $3.8(1 / 26)$ & $0(0 / 13)$ & - \\
\hline & 3 & $1.7(1 / 60)$ & $0(0 / 64)$ & $0(0 / 34)$ & $0(0 / 34)$ & - \\
\hline & 4 & $0(0 / 47)$ & $0(0 / 31)$ & $0(0 / 32)$ & $0(0 / 26)$ & - \\
\hline & 5 & $0(0 / 80)$ & $0(0 / 47)$ & $0(0 / 55)$ & $1.3(1 / 75)$ & - \\
\hline & 6 & $0(0 / 44)$ & $0(0 / 58)$ & $0(0 / 37)$ & $0(0 / 20)$ & - \\
\hline & 7 & $0(0 / 84)$ & $0(0 / 39)$ & $0(0 / 36)$ & $0(0 / 44)$ & - \\
\hline & 8 & $2.2(1 / 45)$ & $2.1(1 / 47)$ & $0(0 / 51)$ & $0(0 / 4)$ & - \\
\hline & 9 & $0(0 / 73)$ & $2.9(1 / 35)$ & $0(0 / 15)$ & $0(0 / 21)$ & - \\
\hline & 10 & $0(0 / 102)$ & $3.2(2 / 63)$ & $0(0 / 33)$ & $71.4(20 / 28)$ & Ear \\
\hline & total & $(3 / 642)$ & $(4 / 504)$ & $(2 / 364)$ & $(21 / 313)$ & \\
\hline \multirow[t]{11}{*}{ B. miyamotoi } & 1 & $0(0 / 75)$ & $2.5(2 / 81)$ & $0(0 / 45)$ & $2.1(1 / 48)$ & - \\
\hline & 2 & $0(0 / 32)$ & $7.7(3 / 39)$ & $0(0 / 26)$ & $0(0 / 13)$ & Spleen \\
\hline & 3 & $3.3(2 / 60)$ & $0(0 / 64)$ & $0(0 / 34)$ & $0(0 / 34)$ & Spleen \\
\hline & 4 & $0(0 / 47)$ & $0(0 / 31)$ & $0(0 / 32)$ & $3.8(1 / 26)$ & - \\
\hline & 5 & $1.3(1 / 80)$ & $0(0 / 47)$ & $0(0 / 55)$ & $1.3(1 / 75)$ & - \\
\hline & 6 & $0(0 / 44)$ & $0(0 / 58)$ & $2.7(1 / 37)$ & $0(0 / 20)$ & - \\
\hline & 7 & $0(0 / 84)$ & $0(0 / 39)$ & $0(0 / 36)$ & $0(0 / 44)$ & - \\
\hline & 8 & $0(0 / 45)$ & $0(0 / 47)$ & $0(0 / 51)$ & $0(0 / 4)$ & - \\
\hline & 9 & $17.8(13 / 73)$ & $14.3(5 / 35)$ & $0(0 / 15)$ & $0(0 / 21)$ & - \\
\hline & 10 & $0(0 / 102)$ & $0(0 / 63)$ & $3(1 / 33)$ & $3.6(1 / 28)$ & - \\
\hline & total & $(16 / 642)$ & $(10 / 504)$ & $(2 / 364)$ & $(4 / 313)$ & - \\
\hline
\end{tabular}


were co-infected with B. burgdorferi (s.l) and B. miyamotoi. Two nymphs (mouse 9, challenge 2 and mouse 10, challenge 4) were co-infected with B. burgdorferi (s.l) and B. miyamotoi. In experiment 2, 2308 engorged fieldcollected larvae were collected, which were not further analysed.

\section{Pathogen transmission by field-collected larvae}

All mice were not infected with B. burgdorferi (s.l) and $B$. miyamotoi at the start of the experiments and all control mice were uninfected at the end of the experiments (Table 3). In experiment 1, 1 week after four challenges with field-collected larvae, 1 out of 10 mice was positive for $B$. afzelii and 2 out of 10 mice for B. miyamotoi. In experiment 2, 3 weeks after three challenges with fieldcollected larvae, 1 out of 10 mice was positive for both

Table 3 Infections in mice of experiments 1 and 2

\begin{tabular}{|c|c|c|c|c|}
\hline & Mouse & Treatment & Before challenges & After challenges \\
\hline \multirow[t]{12}{*}{ Experiment 1} & 1 & $\mathrm{~T}$ & - & - \\
\hline & 2 & $\mathrm{~T}$ & - & $\mathrm{Bm}(\mathrm{S})$ \\
\hline & 3 & $\mathrm{~T}$ & - & $\mathrm{Bm}(\mathrm{S})$ \\
\hline & 4 & $\mathrm{~T}$ & - & - \\
\hline & 5 & $\mathrm{~T}$ & - & - \\
\hline & 6 & $\mathrm{~T}$ & - & - \\
\hline & 7 & $\mathrm{~T}$ & - & - \\
\hline & 8 & $\mathrm{~T}$ & - & - \\
\hline & 9 & $\mathrm{~T}$ & - & - \\
\hline & 10 & $\mathrm{~T}$ & - & $\mathrm{Ba}(\mathrm{E})$ \\
\hline & 11 & $C$ & n.a. & - \\
\hline & 12 & $C$ & n.a. & - \\
\hline \multirow[t]{16}{*}{ Experiment 2} & 13 & $\mathrm{~T}$ & - & - \\
\hline & 14 & $\mathrm{~T}$ & - & - \\
\hline & 15 & $\mathrm{~T}$ & - & - \\
\hline & 16 & $\mathrm{~T}$ & - & $\mathrm{Ba}(\mathrm{E}), \mathrm{Bm}(\mathrm{S}, \mathrm{E})$ \\
\hline & 17 & $\mathrm{~T}$ & - & - \\
\hline & 18 & $\mathrm{~T}$ & - & - \\
\hline & 19 & $\mathrm{~T}$ & - & - \\
\hline & 20 & $\mathrm{~T}$ & - & - \\
\hline & 21 & $\mathrm{~T}$ & - & - \\
\hline & 22 & $\mathrm{~T}$ & - & $\mathrm{Bm}(\mathrm{S})$ \\
\hline & 23 & C & - & - \\
\hline & 24 & $C$ & - & - \\
\hline & 25 & $C$ & n.a. & - \\
\hline & 26 & $C$ & n.a. & - \\
\hline & 27 & C & n.a. & - \\
\hline & 28 & C & n.a. & - \\
\hline
\end{tabular}

$T$ treatment mouse, challenged with larvae, $C$ control mouse, n.a. not analysed $S$ Spleen, $E$ Ear biopsy, Ba Borrelia afzelii, Bm Borrelia miyamotoi

- = uninfected
B. afzelii and B. miyamotoi. We were able to isolate and culture live spirochaetes for more than three passages from the ears of this infected mouse. The motile spirochaetes in this culture and the B. burgdorferi (s.l)-positive tissue samples and nymphs were all identified as $B$. afzelii by molecular typing. In addition, in experiment 2, 1 out of 10 mice was positive for $B$. miyamotoi. None of the rodent samples were infected with Anaplasma phagocytophilum or Neoehrlichia mikurensis (data not shown).

\section{Natural tick burden on field-collected rodents}

In total, 335 wood mice and 521 bank voles were trapped. Total number of nymphs on these rodents was 60 (mean $0.07 \pm 0.013$ ) and total number of larvae 3157 (mean $3.69 \pm$ 0.235 ), resulting in a nymph to larva ratio of 1:52.6.

\section{Discussion}

We showed that larvae of I. ricinus can transmit Lyme disease spirochaetes. An abstract in a conference book from 2002 claimed this finding before, but it was never published in a full research article [26]. The possibility to culture $B$. afzelii from several organs of the rodents shows that the spirochaetes were viable and infectious. The rodents infected with $B$. afzelii subsequently facilitated transmission to other larvae, which successfully moulted to infected nymphs (71.4\% infectivity during the last challenge). This resulted in a higher infection rate in the emerged nymphs compared to the infection rate of questing larvae. These results are in contradiction to the general idea that $B$. burgdorferi (s.l) can only be transmitted by nymphs (and adults), which acquired the infection as a larvae (or nymphs) during feeding [6-8]. We have shown that $0.62 \%$ of the larvae in nature is infected with $B$. burgdorferi (s.l), whereas this is about $10 \%$ (range 0-60 \%) for nymphs [27, 28]. On rodents, which are the main maintenance host for larvae and reservoir host of $B$. afzelii, we found a nymph to larva ratio of 1:52.6, which is in accordance with the ratios found by Gassner et al. [18] and Pisanu et al. [29]. This means that among 1000 feeding nymphs there are 100 infected (10\%) and at the same time 52,600 larvae feed on the same rodent population from which $326(0.62 \%)$ are infected. As a result, assuming comparable transmission efficiencies for larvae and nymphs, larval contribution to rodent infections is approximately three times higher than the nymphal contribution. When transmission efficiency from I. ricinus to rodents is considered to be $100 \%$ for nymphs [30] and $10 \%$ for larvae ( 1 out of 10 larvae, Table 2), larvae are still responsible for a quarter of the infections in rodents. The transmission efficiencies of larvae and nymphs need further research. Regardless of these transmission efficiencies, our results show that B. afzelii can also cycle between larvae through rodents without the interference of nymphs. Infection rates 
of B. burgdorferi (s.l) in questing larvae can even be up to $25.8 \%$, as found in Germany [14], increasing the importance of larval infection.

In The Netherlands, 1.1 million people are bitten by one or more ticks annually [19]. Larvae are responsible for 1.3 to $4.2 \%$ of human tick bites [31-33], and it is estimated that in The Netherlands 30,000 people were bitten by larvae. A significant number of Lyme borreliosis patients did not recognize or remember being bitten by a tick, which might especially be the case for larval ticks due to their minute size (Fig. 1). Our findings provide a reasonable explanation when Lyme borreliosis patients have not noticed a tick bite.

As far as we know, we also showed for the first time that larvae of $I$. ricinus can transmit $B$. miyamotoi. We found a B. miyamotoi infection rate of $2 \%$ in larvae, which is comparable to the infection rate found in nymphs [32, 34]. This suggests a potentially higher contribution of larval tick bites to tick-borne relapsing fever in humans compared to larval contribution to Lyme borreliosis. Other studies have previously suggested an important role for larvae in the transmission of $B$. miyamotoi based on infections coinciding with larval activity and infestation [35, 36]. The contribution of larval transmission to rodents and from rodents to larvae to the enzootic life cycle of $B$. miyamotoi appears to be low. We did not find an increase in the infection rate of larvae with successive challenges, even in the two mice ( 2 and 3 ) that were B. miyamotoi positive after challenge 4. Infection rate of the emerged nymphs was not higher compared to the infection rate in questing larvae. In addition, mouse 9 was infectious to feeding larvae during challenge 1 and challenge 2, but was PCR negative after challenge 4 , suggesting that, in contrast to $B$.

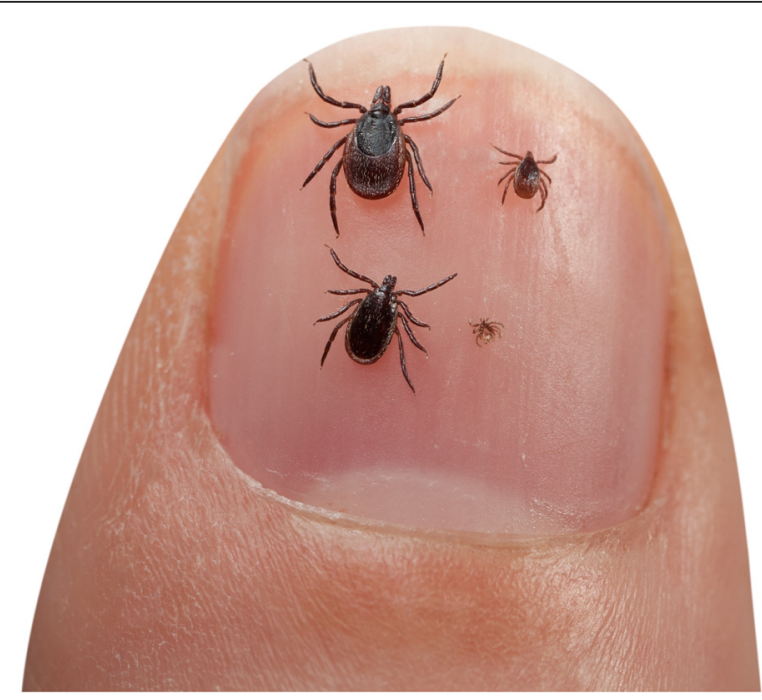

Fig. 1 Developmental stages of I. ricinus. From left to right and top to bottom: Adult female, nymph, adult male, larva (Picture: Hans Smid) afzelii, B. miyamotoi does not cause a persistent infection in rodents [16].

In experiment 1,7 out of 10 mice were exposed to larvae that were (after feeding) B. afzelii-positive and 9 out of 10 mice to $B$. miyamotoi-positive larvae. However, only 1 out of 10 and 2 out of 10 mice were positive after challenge 4 for $B$. afzelii and $B$ miyamotoi, respectively. For $B$. afzelii, this can indicate a low transmission efficiency from larva to rodent, whereas the $B$. miyamotoi infections could have been cleared from the rodents before the dissections after challenge 4. In addition, mice were only naïve during the first challenge because they were challenged 4 times with larvae. This could have resulted in the production of antibodies against B. miyamotoi making the mice resistant to infections during challenge 4.

Knowing now that larvae of $I$. ricinus can transmit $B$. afzelii to rodents, the next question is how larvae can acquire the infection. In theory, larvae may acquire spirochaetes through transovarial transmission from female tick to larvae or through a partial blood meal from a rodent, after which the larva quests for a second host. Transovarial transmission, however, has never been demonstrated for B. burgdorferi (s.l) but is indeed considered an important mechanism for B. miyamotoi $[4,5$, 15]. Partial feeding on an infected rodent for only eight hours incidentally resulted in B. burgdorferi (s.l) infection of $I$. scapularis larvae [37]. In addition, nymphs that have fed for up to $48 \mathrm{~h}$ on one host can thereafter infect another host without first moulting into an adult [38]. Partially engorged larvae, however, were unable to transmit B. burgdorferi (s.l) to a host during a subsequent feeding, which was argued to be because of a too low spirochete load for efficient transmission [37]. However, an inoculum of only 10 spirochaetes has been demonstrated to be sufficient to successfully infect a rodent [39]. Partially-engorged larvae can arise when feeding larvae are detached due to grooming or due to an immune response or death of the host [40-42]. Larvae appear to be unfed macroscopically after up to $18 \mathrm{~h}$ of feeding, during which they may have acquired an infection [37]. Partially-engorged questing nymphs are occasionally observed in the field (GD, pers. obs.). However, frequency of naturally occurring partially engorged and B. burgdorferi (s.l)-infected larvae is unknown. Both mechanisms (transovarial transmission and partial feeding) seem equally unlikely. The route via which larvae can acquire a $B$. burgdorferi (s.l) infection needs further research.

\section{Conclusions}

Larvae of $I$. ricinus can transmit B. afzelii and B. miyamotoi. This finding changes the current view on the enzootic lifecycle of $B$. afzelii and the current public health 


\section{dogma that larval bites cannot cause Lyme disease in humans.}

\section{Competing interests}

The authors declare that they have no competing interests.

\section{Authors' contributions}

GD and GF collected field materials, GD conducted the challenges and drafted the manuscript, CC, AW, MF, JE, AO and GD analysed samples for infection, GF and $\mathrm{JH}$, helped with implementation of the results, and WT and $\mathrm{HS}$ contributed to the design of the study. All authors read and approved the final manuscript.

\section{Acknowledgements}

We thank Marloes van Schaijk and Inge Krijger for their help with the rodent trapping.

This study was financially supported by the Dutch Ministry of Health, Welfare and Sport (VWS). GF was supported by the János Bolyai Research Scholarship of the Hungarian Academy of Sciences. This work was done under the frame of EurNegVec Cost Action TD1303.

\section{Author details}

${ }^{1}$ Laboratory of Entomology, Wageningen University, PO box 166700AA Wageningen, The Netherlands. ' 2 Laboratory for Zoonosis and Environmental Microbiology, National Institute for Public Health and Environment (RIVM), Bilthoven, The Netherlands. ${ }^{3}$ Center for Experimental and Molecular Medicine, Academic Medical Center, University of Amsterdam, Amsterdam, The Netherlands. ${ }^{4}$ Department of Medical Microbiology, Academic Medical Center, University of Amsterdam, Center for Experimental and Molecular Medicine, Amsterdam, The Netherlands. ${ }^{5}$ Department of Parasitology and Zoology, Faculty of Veterinary Science, Szentlstvan University, Budapest, Hungary.

Received: 8 December 2015 Accepted: 17 February 2016 Published online: 20 February 2016

\section{References}

1. Stanek G, Wormser GP, Gray J, Strle F. Lyme borreliosis. Lancet. 2012; 379(9814):461-73.

2. Platonov AE, Karan LS, Kolyasnikova NM, Makhneva NA, Toporkova MG, Maleev $W$, et al. Humans infected with relapsing fever Spirochete Borrelia miyamotoi, Russia. Emerg Infect Dis. 2011;17(10):1816-23.

3. Wagemakers A, Staarink PJ, Sprong H, Hovius JW. Borrelia miyamotoi: a widespread tick-borne relapsing fever spirochete. Trends Parasitol. 2015; 31(6):260-9

4. Richter D, Debski A, Hubalek Z, Matuschka FR. Absence of Lyme disease spirochetes in larval Ixodes ricinus ticks. Vector Borne Zoonotic Dis. 2012; 12(1):21-7.

5. Rollend L, Fish D, Childs JE. Transovarial transmission of Borrelia spirochetes by Ixodes scapularis: a summary of the literature and recent observations. Ticks Tick Borne Dis. 2013;4(1-2):46-51.

6. Piesman J, Sinsky RJ. Ability to Ixodes scapularis, Dermacentor variabilis, and Amblyomma americanum (Acari: Ixodidae) to acquire, maintain, and transmit Lyme disease spirochetes (Borrelia burgdorferi). J Med Entomol. 1988;25(5):336-9.

7. Gern L, Rais O. Efficient transmission of Borrelia burgdorferi between cofeeding Ixodes ricinus ticks (Acari: Ixodidae). J Med Entomol. 1996;33(1):189-92.

8. Voordouw MJ. Co-feeding transmission in Lyme disease pathogens. Parasitology. 2015;142(2):290-302.

9. Radolf JD, Caimano MJ, Stevenson B, Hu LT. Of ticks, mice and men: understanding the dual-host lifestyle of Lyme disease spirochaetes. Nat Rev Microbiol. 2012;10(2):87-99.

10. Kurtenbach K, Peacey M, Rijpkema SG, Hoodless AN, Nuttall PA, Randolph SE. Differential transmission of the genospecies of Borrelia burgdorferi sensu lato by game birds and small rodents in England. Appl Environ Microbiol. 1998; 64(4):1169-74.

11. Fingerle V, Schulte-Spechtel UC, Ruzic-Sabljic E, Leonhard S, Hofmann H, Weber $\mathrm{K}$, et al. Epidemiological aspects and molecular characterization of Borrelia burgdorferi s.l. from southern Germany with special respect to the new species Borrelia spielmanii sp. nov. Int J Med Microbiol. 2008;298(3-4):279-90.
12. Kjelland V, Stuen S, Skarpaas T, Slettan A. Prevalence and genotypes of Borrelia burgdorferi sensu lato infection in Ixodes ricinus ticks in southern Norway. Scand J Infect Dis. 2010;42(8):579-85.

13. Strube C, Montenegro VM, Epe C, Eckelt E, Schnieder T. Establishment of a minor groove binder-probe based quantitative real time PCR to detect Borrelia burgdorferi sensu lato and differentiation of Borrelia spielmanii by ospA-specific conventional PCR. Parasit Vectors. 2010;3(1):69.

14. Tappe J, Jordan D, Janecek E, Fingerle V, Strube C. Revisited: Borrelia burgdorferi sensu lato infections in hard ticks (Ixodes ricinus) in the city of Hanover (Germany). Parasit Vectors. 2014;7(1):441.

15. Scoles GA, Papero M, Beati L, Fish D. A relapsing fever group spirochete transmitted by lxodes scapularis ticks. Vector Borne Zoonotic Dis. 2001;1(1):21-34

16. Taylor KR, Takano A, Konnai S, Shimozuru M, Kawabata H, Tsubota T. Borrelia miyamotoi infections among wild rodents show age and month independence and correlation with Ixodes persulcatus larval attachment in Hokkaido, Japan. Vector Borne Zoonotic Dis. 2013:13(2):92-7.

17. Heylen D, Sprong H, van Oers K, Fonville M, Leirs H, Matthysen E. Are the specialized bird ticks, Ixodes arboricola and I. frontalis, competent vectors for Borrelia burgdorferi sensu lato? Environ Microbiol. 2014;16(4):1081-9.

18. Gassner F, Takken W, Plas CL, Kastelein P, Hoetmer AJ, Holdinga M, et al. Rodent species as natural reservoirs of Borrelia burgdorferi sensu lato in different habitats of Ixodes ricinus in The Netherlands. Ticks Tick Borne Dis. 2013;4(5):452-8

19. Hofhuis A, Harms MG, van der Giessen JWB, Sprong H, Notermans DW, van Pelt W. Ziekte van Lyme in Nederland 1994-2009. Infectieziekten Bulletin. 2010;21(3):84-7.

20. Milne A. The comparison of sheep-tick populations (Ixodes ricinus L.). Ann Appl Biol. 1943;30(3):240-50.

21. Wagemakers A, Oei A, Fikrig MM, Miellet WR, Hovius JW. The relapsing fever spirochete Borrelia miyamotoi is cultivable in a modified Kelly-Pettenkofer medium, and is resistant to human complement. Parasit Vectors. 2014;7(1):418.

22. Jahfari S, Coipan EC, Fonville M, van Leeuwen AD, Hengeveld P, Heylen D, et al. Circulation of four Anaplasma phagocytophilum ecotypes in Europe. Parasit Vectors. 2014;7(1):365

23. Schouls LM, Van De Pol I, Rijpkema SGT, Schot CS. Detection and identification of Ehrlichia, Borrelia burgdorferi sensu lato, and Bartonella species in Dutch Ixodes ricinus ticks. J Clin Microbiol. 1999;37(7):2215-22.

24. Hovius JW, de Wever B, Sohne M, Brouwer MC, Coumou J, Wagemakers A, et al. A case of meningoencephalitis by the relapsing fever spirochaete Borrelia miyamotoi in Europe. Lancet. 2013;382(9892):658.

25. Coipan EC, Fonville M, Tijsse-Klasen E, van der Giessen JWB, Takken W, Sprong $\mathrm{H}$, et al. Geodemographic analysis of Borrelia burgdorferi sensu lato using the 5S-23S rDNA spacer region. Infect Genet Evol. 2013;17: 216-22.

26. Hammer B, Meiners T, Marangoni A, Sambri V, Göbel UB, Kahl O. Borrelia burgdorferi sensu lato transmission from tick vector to host: experimental evidence of the involvement of the larval stage of Ixodes ricinus. Int J Med Microbiol. 2002;291(Supplement 33):211.

27. Rauter C, Hartung T. Prevalence of Borrelia burgdorferi sensu lato genospecies in Ixodes ricinus ticks in Europe: a metaanalysis. Appl Environ Microbiol. 2005; 71(11):7203-16

28. Gassner F, Van Vliet AJH, Burgers SLGE, Jacobs F, Verbaarschot P, Hovius EKE, et al. Geographic and temporal variations in population dynamics of ixodes ricinus and associated borrelia infections in the Netherlands. Vector Borne Zoonotic Dis. 2011;11(5):523-32.

29. Pisanu B, Marsot M, Marmet J, Chapuis JL, Reale D, Vourc'h G. Introduced Siberian chipmunks are more heavily infested by ixodid ticks than are native bank voles in a suburban forest in France. Int J Parasitol. 2010;40(11):1277-83.

30. Kahl O, Janetzki-Mittmann C, Gray JS, Jonas R, Stein J, De Boer R. Risk of infection with Borrelia burgdorferi sensu lato for a host in relation to the duration of nymphal Ixodes ricinus feeding and the method of tick removal. Zentralbl Bakteriol. 1998;287(1-2):41-52.

31. Hofhuis A, Herremans T, Notermans DW, Sprong H, Fonville M, van der Giessen JW, et al. A prospective study among patients presenting at the general practitioner with a tick bite or erythema migrans in The Netherlands. PLoS One. 2013:8(5):e64361.

32. Fonville $M$, Hengeveld $P$, Docters van Leeuwen A, Jahfari S, Harms MG, van Vliet AJH, et al. Blootstelling aan Borrelia miyamotoi door tekenbeten. Infectieziekten Bulletin. 2013;24(10):4. 
33. Lindblom P, Wilhelmsson P, Fryland L, Sjöwall J, Haglund M, Matussek A, et al. Tick-borne encephalitis virus in ticks detached from humans and follow-up of serological and clinical response. Ticks Tick Borne Dis. 2014;5(1):21-8.

34. Richter D, Schlee DB, Matuschka FR. Relapsing fever-like spirochetes infecting European vector tick of Lyme disease agent. Emerging Infect Dis. 2003;9(6):697-701.

35. Barbour AG, Bunikis J, Travinsky B, Hoen AG, Diuk-Wasser MA, Fish D, et al. Niche partitioning of Borrelia burgdorferi and Borrelia miyamotoi in the same tick vector and mammalian reservoir species. Am J Trop Med Hyg. 2009;81(6):1120-31.

36. Molloy PJ, Telford III SR, Chowdri HR, Lepore TJ, Gugliotta JL, Weeks KE, et al. Borrelia miyamotoi disease in the northeastern United States a case series. Ann Intern Med. 2015;163(2):91-8.

37. Piesman J. Experimental acquisition of the Lyme disease spirochete, Borrelia burgdorferi, by larval Ixodes dammini (Acari: Ixodidae) during partial blood meals. J Med Entomol. 1991;28(2):259-62.

38. Shih CM, Spielman A. Accelerated transmission of Lyme disease spirochetes by partially fed vector ticks. J Clin Microbiol. 1993;31(11):2878-81.

39. Barthold SW. Infectivity of Borrelia burgdorferi relative to route of inoculation and genotype in laboratory mice. J Infect Dis. 1991;163(2):419-20.

40. Trager W. Acquired immunity to ticks. J Parasitol. 1939;25(1):57-81.

41. Brossard M, Wikel SK. Tick immunobiology. Parasitology. 2004;129:S161-76.

42. Levin ML, Fish D. Density-dependent factors regulating feeding success of Ixodes scapularis larvae (Acari: Ixodidae). J Parasitol. 1998;84(1):36-43.

\section{Submit your next manuscript to BioMed Central} and we will help you at every step:

- We accept pre-submission inquiries

- Our selector tool helps you to find the most relevant journal

- We provide round the clock customer support

- Convenient online submission

- Thorough peer review

- Inclusion in PubMed and all major indexing services

- Maximum visibility for your research

Submit your manuscript at www.biomedcentral.com/submit
Biomed Central 